\title{
INSPIRE: A new opportunity for cancer pharmacoepidemiology research
}

\author{
Espen Enerly ${ }^{a *}$, Lena Holmstrøm ${ }^{\mathrm{b}}$, Anna Skog ${ }^{\mathrm{b}}$, Kristin Oterholt Knudsen ${ }^{\mathrm{b}}$, Jan F. Nygård ${ }^{\mathrm{c}}$, \\ Bjørn Møller ${ }^{\mathrm{b}}$ and Giske Ursin ${ }^{\mathrm{d}}$ \\ ${ }^{a}$ Department of Research, Cancer Registry of Norway, Norway \\ ${ }^{\mathrm{b}}$ Department of Registration, Cancer Registry of Norway, Norway \\ ${ }^{\mathrm{c}}$ Department of Registry Informatics, Cancer Registry of Norway, Norway \\ ${ }^{\mathrm{d}}$ Cancer Registry of Norway, Norway \\ *Corresponding author at: Department of Research, Cancer Registry of Norway, Ullernchausseen 64, NO-0379 Oslo, Norway \\ E-mail: espen.enerly@kreftregisteret.no Telephone:+4722928800
}

\begin{abstract}
Until recently, there has been limited overview of the hospital administered cancer medications. The Cancer Registry of Norway has the approval to collect data on medical oncology treatment provided to each patient, but the reporting has so far been manual, time consuming and incomplete. Apart from conducting costly chart reviews, it has not been possible to carry out studies on hospital administered cancer medications. Efforts trying to improve manual reporting have not been sufficient and the most effective way of collecting data on cancer medications is through the hospital systems used for ordering/administering medical oncological treatment. The INSPIRE (INcreaSe PharmaceutIcal REporting) project was initiated to automatically and electronically collect data on cancer medication from the hospitals systems to the Cancer Registry. The project is a unique collaboration between 12 pharmaceutical companies, the Association of Pharmaceutical Companies in Norway, the Norwegian Cancer Society, Inven2, the Cancer Registry of Norway and the four Regional Health Trusts. In this article we describe the INSPIRE project, the data collection, and when and what kind of data that will be available. These new medication data at the Cancer Registry provide new opportunities for cancer pharmacoepidemiology research in Norway.
\end{abstract}

This is an open access article distributed under the Creative Commons Attribution Licence, which permits unrestricted use, distribution, and reproduction in any medium, provided the original work is properly cited.

\section{INTRODUCTION}

In general cancer treatments consist of surgery, radiation therapy and various medical therapy such as chemotherapy, immunotherapy, targeted therapy or hormone therapy. While the Cancer Registry of Norway has extensive overview of patients' surgical procedures and the radiotherapy treatments, data on medical oncological treatment have been lacking in the registry (1). Other sources of cancer medication in Norway are the Norwegian Prescription Database, NorPD (2) and the Norwegian Patient Registry, NPR (3). NorPD contains a complete coverage of dispensed drugs to patients in ambulatory care. This includes dispensed cancer medication that patients take at home, such as protein kinase inhibitors. NorPD is currently under modernization to become "Legemiddelregisteret", the Norwegian Prescribed Drug Registry (the new English name not finally decided) (4). The Patient Registry (NPR) covers all public specialist health-care services in Norway (3). Private institutions and medical specialists providing service for the regional health authority are also included in NPR, as are data on reimbursement for medications prescribed by specialist health care services (so called H-prescriptions, further explanations below). However, a detailed overview including hospital administrated medications linked to detailed clinicopathological features has been lacking in Norway.
The Cancer Registry of Norway is an official health registry covering all cancer cases in Norway back to 1953. It is regulated by the Cancer Registry legislation ("Kreftregisterforskriften"). The legislation states that the main objectives of the Cancer Registry is registration of cancer cases, research on cancer and information activities related to cancer ("Kreftregisterforskriften $\S$ $1-3$ "). Reporting to the Cancer Registry is mandatory for all medical doctors and includes all aspects of cancer, including details on diagnosis and treatment. Registration does not require patient consent. The Cancer Registry publishes reports on cancer statistics and trends each year, including more detailed reports from the eight clinical registries. Data in the registry can be made available to anyone with the necessary approvals (for example ethical approval for research purposes), as long as the intended use is within the registry's objectives.

A challenge with the existing electronic, although mandatory, reporting to the Cancer Registry has been the low completeness of reporting on administered cancer medications (1). The lack of medication data has made it difficult to describe the national standard of care, to identify regional differences and to measure adherence to clinical guidelines. Consequently, the lack of data has limited the opportunities for cancer pharmacoepidemiology research in this area.

It is essential to have knowledge on cancer medica- 
tion therapy administered at the hospitals (as well as other types of therapy), to be able to monitor and evaluate clinical guidelines and whether health services are equally available in all of Norway. It has been a paradox that the extensive health technology assessment prior to a cancer medication is introduced in clinical care, has not been possible to easily follow-up systematically for quality control and for research. With many new cancer medications and combination treatments being introduced, some given to small patient groups, research of its pattern of use and effectiveness is needed.

The aim of the INSPIRE project was to capture cancer medication data more or less automatically from hospital systems that support cancer medication, and underway expanded to include H-prescriptions from NPR, and to make it available for research and clinical quality assessment through the Cancer Registry.

\section{FRAMEWORK OF INSPIRE}

With a common goal to increase the cancer medication reporting, the INSPIRE project was initiated as a collaboration between the Cancer Registry of Norway, the Association of Pharmaceutical Companies in Norway (LMI) and the technology transfer office Inven2. With the initial framework in place between these main partners, agreements were made between the Cancer Registry of Norway and a total of twelve pharmaceutical companies as well as the Norwegian Cancer Society. The level of funding required was estimated to NOK 6.8 million and in addition to in-kind contribution from the Cancer Registry each of the participants contributed with NOK 400000 up to 800000 .

The first project to be initiated was INSPIRE:lung cancer, a pilot project with the aim to establish the overall data capture and process medical information on lung cancer patients. Data on all cancer types were collected, but the data curation and processing was restricted to lung cancer. Lung cancer was chosen as the initial project because of the common use of antineoplastic and immunomodulating agents in the treatment and the high incidence and severity of the disease.

The Cancer Registry has been the project owner, project manager and responsible for carrying out the project. A steering committee with representatives from the main partners as well as all the four Regional Health Authorities was established in addition to a sub-board were each of the pharmaceutical companies were represented. In addition, an advisory board was established with representatives from the Norwegian Institute of Public Health, the Norwegian Patient Registry, the Norwegian Medicine Agency, the Norwegian Hospital Procurement Trust, and a lung cancer oncologist from Oslo University Hospital, in addition to the Association of Pharmaceutical Companies in Norway (LMI), and the Cancer Society.

\section{FROM WHICH TIME PERIOD AND WHAT CANCER MEDICATION VARIABLES ARE COLLECTED?}

A prerequisite for data collection is that hospitals are using electronic systems for administering cancer medications from which the data can be captured. Two software systems are in use in the Southeastern, Western and Central Norway Regional Health Trusts (Chemotherapy Management System (CMS), and CSAM Cytodose). Data collection was limited to these three regions and the time periods when systems have been in place (Figure 1). For these regions all hospitals, except private clinics, are included in the data capture. Data collection from the Northern Regional Health Authority will be established when a system similar to the other regions are operational.

A large part of antineoplastic medication is provided and administered in the hospitals, due to these being administered intravenously (most common) and/or due to the need for active observation of the patient after drug administration. With the use of IT-systems specifically designed to aid this type of treatments, the Cancer Registry can capture data on cancer medication treatment directly from the IT-systems, without the need for time consuming manual reporting.

Cancer treatment can also be administered at home as tablets or simple injections the patient can administer themselves. When the medication is prescribed by the specialist health care, and costs are covered by the health trust, these are called H-prescriptions. This differs from other prescriptions where the state and the patient share the costs. The H-prescriptions are not only available through the prescription database (NorPD) like all other prescriptions, but all H-prescription data are also reported to the Patient Registry (NPR). This is an important distinction because NorPD has very strict personal confidentiality demands that (as of now) does not give the Cancer Registry the opportunity to link a prescription to a specific cancer patient and also save it with other Cancer Registry data (even though the Cancer Registry has a legal approval to contain the information). However, the H-prescriptions reported to NPR can be made available to the Cancer Registry, because both registries can share data for specific purposes. This gives the Cancer Registry the ability to have an overview of all types of cancer treatment, no matter where or how they have been administered. The Cancer Registry receives data from the Norwegian Patient Registry on a regular basis regarding all cancer relevant information on hospital visits. As of January 2019, this includes data on cancer relevant H-prescriptions.

Endocrine therapy is not included in the $\mathrm{H}$ prescriptions, meaning that the Cancer Registry does not have information on hormonal therapy (for example antioestrogen to breast cancer patients). The other exception is oral cancer drugs administered in clinical 


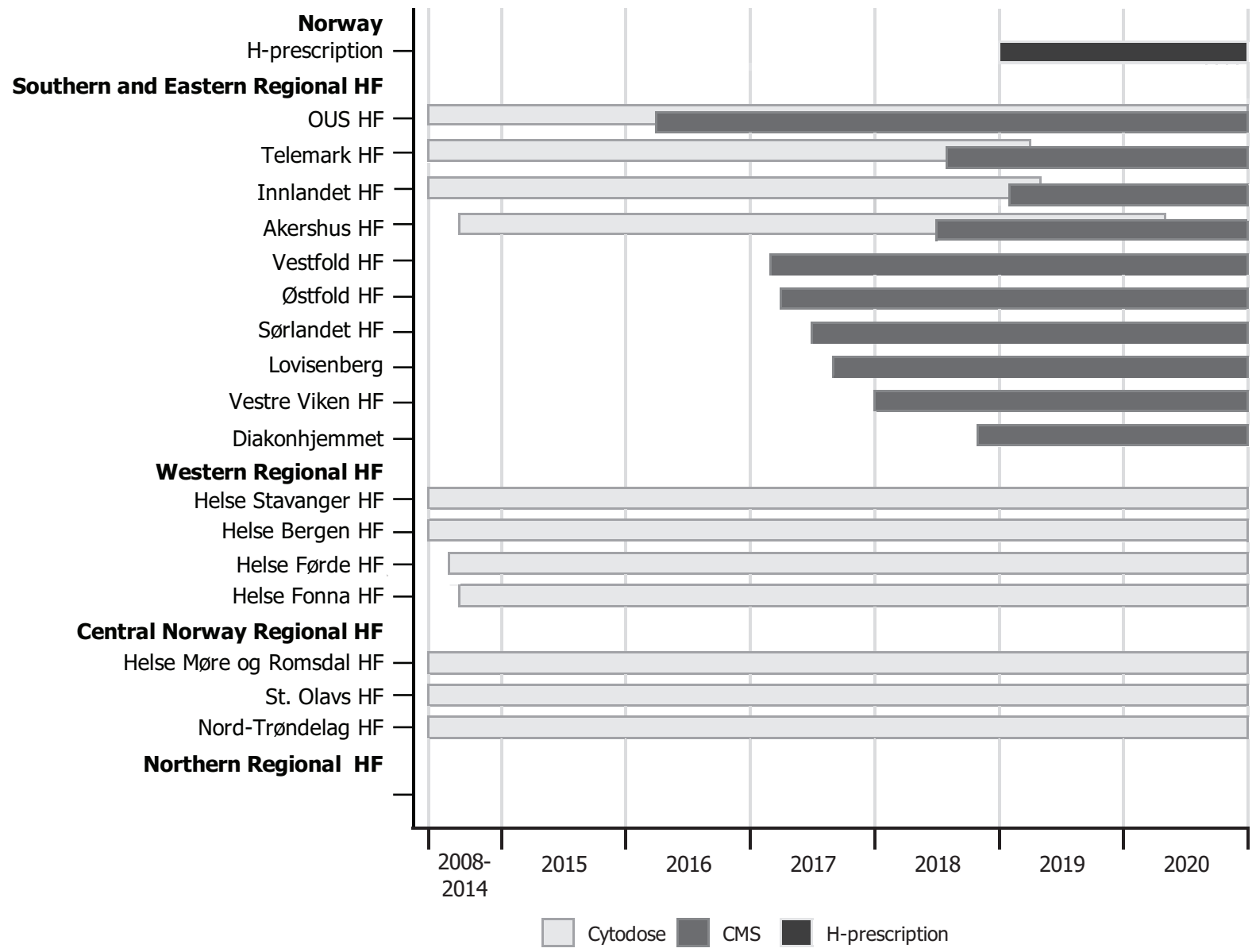

Figure 1. Data capture from health trusts and the Norwegian Patient Registry (H-prescriptions). Modified reproduction from the INSPIRE:lung cancer report (6). The capture starts the date of first date of cancer medication administration in the dataset (not restricted to lung cancer).

\begin{tabular}{|c|c|c|c|}
\hline \multicolumn{2}{|c|}{ Hospital administered medication } & \multicolumn{2}{|c|}{ Medication taken at home (H-prescription) } \\
\hline Variable & Example/unit & Variable & Example \\
\hline Patient ID & $P I N(11$ digit $)$ & Patient ID & $P I N(11$ digit $)$ \\
\hline Height & $\mathrm{cm}$ & Date of dispensing & Date \\
\hline Weight & $\mathrm{kg}$ & Substance ID & 97833 \\
\hline Regimen name & cisplatin/etoposide iv/po & Substance name & Vepesid kaps $50 \mathrm{mg}$ \\
\hline Date of administration & Date & ATC & L01CB01 \\
\hline Route of administration & intravenous & ATC name & etoposid \\
\hline Dose and unit & $40 \mathrm{mg}$ & Hospital ID & Oslo University Hospital HF \\
\hline Active substance & etoposid & ICD-10 & C34 \\
\hline Hospital ID & Oslo University Hospital HF & & \\
\hline ICD-10 (added by the $C R N$ ) & NA & & \\
\hline
\end{tabular}

Figure 2. Comparison of variable type and structure from data sources of medications administered at the hospital and at home. Abbreviations: iv=intravenous, $\mathrm{po}=$ per oral, kaps=capsule.

studies. The Cancer Registry cannot capture this information because study drugs given orally are not administered using neither cancer treatment IT-systems nor H-prescriptions.

Data collection is based on the Cancer Registry making available a list of cancer patients who live in and/or have been treated in the region in question, to the health trusts. Each health trust then extracts information from their respective cancer medication system. The list of cancer patients provided by the Cancer Registry is used by the health trusts to remove information on any oncology medication administered to non-cancer patients from the dataset. This is because some cancer medications have non-cancer indications, such as rituximab to arthritis patients. Only variables specified by the Cancer Registry are reported. The mandatory variables include hospital id, patient id, patient height and weight, drug regimen name, date of drug administration, active substances, dose, dose unit, and route of administration (Figure 2). The primary key for linking data to a specific patient is the patient id, which is the personal identification number assigned to all citizens 
at birth or to immigrants after arrival. The cancer medication data from hospitals are different from the data the Cancer Registry receives from the Patient Registry on medications taken at home (H-prescriptions). The two data sources have different types of data and also a different structure of the variables (Figure 2).

\section{HOW AND WHEN CAN CANCER MEDICATION DATA BE ACCESSED?}

The INSPIRE project was initiated to establish a method for data collection in line with the Cancer Registry regulations. Therefore, access to data follows the same guidelines as for all data at the Cancer Registry. Any researcher with the necessary approvals can apply for personally identifiable data. Application for this is also done at www.helsedata.no which guides the applicant to necessary approvals required for research data (5). The cancer medication data are incorporated with other data at the Cancer Registry and can be linked to other sources such as the Norwegian Patient Registry and the Norwegian Prescription Database, NorPD. In addition, the Cancer Registry will publish reports and summaries showing use of relevant medications annually, as a part of the clinical registries' annual reports.

The INSPIRE:lung cancer project was finalized in April 2021 (6). It is estimated that lung cancer medication data can be applied for in research projects by summer/fall 2021. The plan is that an annual update of data will coincide with the yearly release of the Cancer in Norway report (currently September). Specifically, the data that will be available are:

- Availability of drug cancer treatment for lung cancer o Summer 2021, for lung cancer patients with diagnostic years until 2019

o October 2021, for lung cancer patients until the year of diagnosis 2020

- Yearly updates available after the Cancer in Norway publication every year

- Availability of drug cancer treatment for breast cancer

○ Earliest 2nd quarter 2022, for breast cancer patients with diagnosis year until 2020

○ Autumn 2022, for breast cancer patients until the year of diagnosis 2021

- Yearly updates after Cancer in Norway every year

- Availability of drug cancer treatment for all other cancer diagnoses

○ To be decided

\section{WHAT ARE THE CURRENT LIMITATIONS IN THE MEDICATION DATA CAPTURE?}

Improving data collection and quality is a continuous process. Even though the INSPIRE-project has collected a substantial part of cancer medications in Norway, there is still medication information that is missing.
Currently, information about cancer medications used in the Northern Regional Health Trust is missing and will be included in the data capture when a system similar to the other regions is operational. Roughly $11 \%$ of lung cancer patients were diagnosed in this region in 2019 (1). Information on their hospital administered cancer medications is therefore currently missing.

Although the historic medication data in INSPIRE is comprehensive, it is not complete back to 2008 for all included hospitals as some started using cancer medication systems at a later date (Figure 1). In addition, cancer medication the patients take at home are only available back to January 2019 from NPR. Prescription data prior to 2019 is available in NorPD.

Medications taken orally in clinical studies are also missing from the data capture. These medications are not registered in the systems that the INSPIRE-project use for its data capture. For lung cancer that typically includes inhibitors of tyrosine kinases. A noteworthy exemption is medications from blinded clinical studies. The information captured in these cases states that medication A or placebo has been administered to the patient, meaning there is no information on which medication was given. Care should therefore be taken when performing research on populations where a subset of patients are known to have been included in blinded clinical trials. The data capture is restricted to what is registered in the medication management systems. Therefore, information about side effects of treatment and reasons for discontinuation or change of treatment is not captured.

Finally, drugs prescribed to patients using "blå resept", a subset of prescribed drugs, is not part of the INSPIRE data capture. For cancer treatment this includes endocrine therapy, which is a large part of the treatment for hormonally active cancers. These drugs are available in NorPD and the upcoming "Legemiddelregisteret" $(4,7)$. Lack of this information is not a limitation for lung cancer research as these drugs are not part of lung cancer treatment. However following the INSPIRE lung cancer is the INSPIRE breast cancer. Here, the lack of data on hormonal treatment will have a negative impact as endocrine therapy is commonly used as treatment in breast cancer patients.

Finally, information on cancer medications administered at private clinics (e.g Aleris and Kreftklinikken) is not part of the data capture, but will be addressed in the future. This may be of particular interest for research on the influence of socioeconomic factors and access to novel cancer medications.

\section{OPPORTUNITIES FOR PHARMACO- EPIDEMIOLOGY RESEARCH}

With access to national data on both cancer medications given in hospitals and on $\mathrm{H}$-prescriptions, new research opportunities open up both in pharmacoepidemiology and health care research. First and foremost, there will be an opportunity for a wide range of observational 
studies on clinical use of medications with marketing authorization. First out may be basic descriptive studies to answer questions on the actual standard of cancer medication care. Another question is to what extent the actual cancer medication use, mirrors the clinical guidelines, and how quickly changes to guidelines are adopted at the various hospitals. Furthermore, a study on lung cancer treatment in Norway concluded that surgery and radical and palliative radiotherapy were under-used among the elderly, those with a lower socioeconomic status and those living in certain health trusts (8). With data access to cancer medication use, e.g. immunotherapies and antineoplastic medicines, such studies can be expanded to also cover the use of cancer medication. More elaborative studies may address aspects of comparative effectiveness, e.g. to what extent does the effectiveness of cancer medications mirror the effects seen in clinical trials? This will be particularly relevant as the trial population and intensity of follow up usually differs from a real-world population. With precision medicine the trial populations targeted by medications may become smaller than before, which would cause greater uncertainties in estimating the size of the effect of the medication at the time of marketing authorization and during the health technology assessment. Medication data from the Cancer Registry showing the current standard of care can become an important supplement to health economic evaluations in the health technology assessments. Finally, the value for the patient is the sum of all activities related to the patient's treatment. Now, there is a comprehensive overview of the three cornerstones of cancer care, surgery, radiation therapy and medical therapy. This brings new opportunities for research on a nationwide population and to study the interactions between the components of the overall cancer care.

\section{CONCLUSION}

Antineoplastic and immunomodulating medications administered in the hospitals have been lacking in Norwegian registries and therefore have been hard-to-reach data for research. With the addition of information on cancer medication for lung cancer to the Cancer Registry (other cancers to follow), new opportunities are created for pharmacoepidemiology research in Norway.

\section{Ethical considerations}

Data Protection Impact Assessment (DPIA) was performed by the Cancer Registry for the new data elements collected from the hospitals. This was approved by the Data Protection officer. Technical solutions have undergone mandatory risk assessment. The activities and data in this project are regulated by the Cancer Registry legislation ("Kreftregisterforskriften") and ethical approval is not needed.

\section{Funding}

Funding for this research was provided by the Norwegian Cancer Society, and the following pharmaceutical companies: Abbvie AS, Amgen AB Norge NUF, AstraZeneca AB, Bristol-Myers Squibb Norway Ltd, Janssen-Cilag AS, Merck AB NUF, MSD (Norge) AS, Novartis Norge AS, Pfizer Norge AS, Roche Norge AS, Sanofi-Aventis Norge AS, Takeda AS.

\section{Project website}

https://www.kreftregisteret.no/Forskning/Prosjekter/inspire2/

\section{REFERENCES}

1. Årsrapport 2019 med resultater og forbedringstiltak fra Nasjonalt kvalitetsregister for lungekreft. Oslo, 2020.

2. Furu K. Establishment of the nationwide Norwegian Prescription Database (NorPD) - new opportunities for research in pharmacoepidemiology in Norway. Norsk Epidemiologi 2009; 18 (2): 129-136.

3. Bakken IJ, Ariansen AMS, Knudsen GP, Johansen KI, Vollset SE. The Norwegian Patient Registry and the Norwegian Registry for Primary Health Care: Research potential of two nationwide health-care registries. Scand J Public Health 2020; 48 (1): 49-55.

4. Sommerschild HT, Berg CL, Jonasson C, Husabø KJ, Sharikabad MN. Data resource profile: Norwegian Databases for Drug Utilization and Pharmacoepidemiology. Norsk Epidemiologi 2021; 29 (1-2) : 7-12.

5. Helsedata. Data access [Web page]. The Directorate for e-Health, 2021 [cited 2021 14.04]. Available from: https://helsedata.no/en/.

6. INSPIRE:lungekreft, evaluering av pilotprosjekt. Oslo, Norway: The Cancer Registry of Norway, 2021.

7. LMR-forskriften. Forskrift om innsamling og behandling av helseopplysninger i Legemiddelregisteret, 2021.

8. Nilssen Y, Strand TE, Fjellbirkeland L, Bartnes K, Brustugun OT, O'Connell DL, et al. Lung cancer treatment is influenced by income, education, age and place of residence in a country with universal health coverage. Int $J$ Cancer 2016; 138 (6): 1350-60. 